\title{
Forced sexual experiences and sexual situation self-efficacy among South African youth
}

Jacqueline A. Miller, Edward A. Smith, Donna Coffman, Catherine Mathews and Lisa Wegner

\begin{abstract}
Nearly 20\% of South African youth experience forced or coerced sexual intercourse. Understanding the factors associated with forced sex is important for informing prevention programs aimed at reducing sexual violence and HIV and AIDS. Multilevel regression models test the association between sexual situation self-efficacy and forced sex among 2,893 South African adolescents. Findings suggest that youth are more likely to experience forced sex after periods of time when their levels of self-efficacy are lower than their average levels of self-efficacy. Furthermore, youth who are lower on their self-efficacy compared to their peers are more likely to experience forced sex. Implications for prevention research are discussed.
\end{abstract}

By age 16, nearly one of every five South African youth, both male and female, report experiencing forced or coerced sex (Andersson et al., 2012). Yet interventions aimed at reducing sexual risk behavior and preventing the transmission of HIV often assume (perhaps implicitly) that sexual activity is volitional. The lack of control in a forced sexual encounter limits an individual's ability to use condoms and other protective behaviors, increasing youths' risk for unwanted pregnancies and sexually transmitted infections (Abma, Driscoll, \& Moore, 1998; Maharaj \& Munthree, 2007; Vundule, Maforah, Jewkes, \& Jordaan, 2001). In South Africa, where an estimated 5.6 million people are living with HIV and AIDS (UNAIDS, 2013), the repercussions of forced sex are particularly salient. Consequently, it is important to understand what factors interventions can target to help youth gain control in their sexual lives and reduce their susceptibility to forced sex.

International organizations, such as the World Health Organization (WHO), USAIDS, UNICEF, and individual countries have attempted to reduce the prevalence of sexual violence through the implementation of prevention programs and policy reform. In the United States, university initiatives to reduce sexual violence have become widespread (Anderson \& Whiston, 2005; Daigle, 2009) and programs geared toward safe dating in high schools have begun to emerge (Foshee et al., 1998; Jaycox et al., 2006; for review see De Koker, Mathews, Zuch, Bastien, \& Mason-Jones, 2014). Despite the high prevalence of forced sex in South Africa, similar school-based dating violence prevention programs are only just beginning to emerge (South African Medical 
Research Council [SAMRC], 2012). Nonetheless, it is unclear how prevention programs should address sexual violence because the empirical research on factors that increase South African youth's susceptibility to forced sex is limited. However, emerging research points to attitudes toward masculinity and violence, alcohol use, and poor conflict resolution skills as contributing factors to intimate partner violence (IPV) among adolescents (Russell et al., 2014).

Perceptions of control in one's own life, or self-efficacy, are strong contributors to one's ability to influence the actual course of one's life and the events around them (Bandura, 1989). Although many sexual health interventions aim to strengthen adolescent's self-efficacy to refuse sex and control sexual encounters, a lack of control is an inherent characteristic of forced sexual experiences because these experiences are against one's will. Maharaj and Munthree (2007) report that South African girls whose sexual initiation was forced are less likely to feel confident in their ability to convince their partner to use a condom. The authors suggest that experiences of forced sex may increase fears and reduce girls' ability to negotiate safer sex; however, due to the crosssectional nature of this study, the direction of the relationship is unclear. Youth in the United States who have high self-efficacy to avoid forced sex are less likely to experience forced sex by a date or peer (Walsh \& Foshee, 1998), suggesting that self-efficacy may help prevent forced sexual encounters. Believing in one's own ability to exercise control in sexual encounters can help reduce risky sexual behaviors (Cooper, Shapiro, \& Powers, 1998). It is unclear whether low self-effi- cacy is a risk factor for or a result of forced sexual experiences. The distinction is important as a failure to recognize this relationship may undermine intervention efforts. Although self-efficacy does not insure that one has sexual agency-the ability to enact willful decisions regarding one's sexual life (Crown \& Roberts, 2007) - self-efficacy is critical for agency (Bandura 1977).

\section{What Is Forced Sex?}

The WHO's definition of rape (Krug, Dahlberg, Mercy, Zwi, \& Lozano, 2002, p. 149) and Heise, Moore, and Toubia's (1995) widely cited definition of sexual coercion are nearly identical, proposing that rape or sexual coercion is any nonconsensual sex involving penetration acquired through the use of force, regardless of one's gender. Nonetheless, the meaning of these terms varies widely both in the literature and colloquially, with the term rape sometimes being reserved for encounters that involve physical violence. The term forced sex appears to be a more intuitive definition that captures the idea that a sexual experience is non-consensual and is acquired through some means of force. However, this term is still open to interpretation based on what one considers constitutes "force." Heise and colleagues suggest that the mechanisms of force used in sexual coercion lie on a continuum, including physical violence, psychological tactics, and social or economic pressures and obligations. In South Africa, as in many countries, verbal and psychological tactics to acquire sex are illegal and legally constitute forced sex; however, such tactics do not constitute force in the eyes of many South Africans, where relentless pleading and pressure are seen as forms of seduction (Wood, 2005). Nonetheless, research has found that forced sex involving incapacitation through drugs or alcohol, physical violence, and verbal coercion has negative psychological consequences (Brown, Testa, \& Messman-Moore, 2009), suggesting that using a broader definition of forced sex is important for understanding 
its implications for youth. The term forced sex in the current article will include all instances of nonconsensual sex including rape and coercion.

\section{Sexual violence in South Africa}

Most research on forced sex focuses on women and girls, due to power inequalities between girls and boys. In a model of IPV (Jewkes, 2002) including sexual violence, Russell et al. (2014) found that greater belief in male superiority and acceptance of violence were associated with recent reports of IPV victimization among girls and IPV perpetration among boys. Girls often do not feel they can refuse sex with their partner in fear that a refusal would lead to being beaten or that their boyfriends would leave them (Jewkes, Vundule, Maforah, \& Jordaan, 2001). Additionally, 30\% of all youth do not believe a girl has the right to refuse their boyfriend's sexual advances (Andersson et al., 2004). Given the levels of fear and lack of control within a relationship, it is not surprising that nearly three-quarters of sexually active girls report that their first sex was against their will (Jewkes et al., 2001), suggesting that sexual coercion may be far more common than is often reported.

In spite of the gender inequalities, research suggests that boys are not immune to sexual victimization. According to the South African National Youth Risk Survey (Reddy et al., 2010), $7.0 \%-15.2 \%$ of boys and $2.8 \%-12.9 \%$ of girls report ever experiencing forced sex (reports vary by age). Overall, this report suggests that experiences of forced sex may be higher for boys (11.9\%) than girls (8.2\%). Andersson and Ho-Foster (2008) suggest that rates of lifetime experiences of forced sex among 18-year-old male youth may be as high as $44 \%$. However, King and colleagues found girls' odds of experiencing forced sex were 3.9 times greater than boy's odds. These contrasting findings may be due to both the age of participants and region of the sample. Research suggests that forced sex is more common among young boys than young girls, but among older adolescents (ages 15-19), forced sex is more common among girls than boys (Andersson et al., 2004). Nevertheless, over two-thirds of male

and female perpetrators of forced sex were also victims of forced sex themselves (Andersson et al., 2004), suggesting that understanding forced sex experiences is important for both male and female youth.

\section{Sexual socialization and forced sex}

Exposure to discussions, attitudes, and knowledge of sexuality (through family, peers, or media) shapes youths' understanding of sexual norms and perceived consequences of sex (Bandura, 1977). Social norms regarding masculinity and femininity may inhibit youths' development and ability to express sexual agency, which may increase their risk for forced sex. In a review of literature from developing countries, Jejeebhoy and Bott (2003) found that gender norms that encourage male toughness and dominance may perpetuate sexual violence and diminish communication about sexual matters. Russell et al. (2014) found that attitudes supportive of masculine superiority and violence were associated with increased male perpetration of IPV and IPV victimization of girls among South African youth. However, these attitudes may also contribute to victimization of boys. South African norms on masculinity prescribe a strong libido and numerous sexual conquests, creating pressure for boys to engage in 
sex regardless of their own will (Petersen, Bhana, \& McKay, 2005; Selikow, Ahmed, Flisher, Mathews, \& Mukoma, 2009). Boys, for example, who are not sexually active are often rejected by peers; likewise, having few sexual partners or using condoms may also be cause for teasing and ostracizing.

Pressure for boys to engage in sex is not limited to male peers. Girls may also force boys into a sexual relationship by threatening to tell others that the boy did not desire to have sex (Selikow et al., 2009). Testing a model of IPV toward women, Russell et al. (2014) found that poor conflict resolution skills among both girls and their partners were associated with recent IPV. Both girls and boys in South Africa lack communication skills to negotiate sexual experiences, leaving violence and coercion as the primary mechanism for exerting one's will (Wood \& Jewkes, 1997). Greater sexual agency may help youth communicate their desired sexual behaviors and reduce coercive sex, particularly in the context of a relationship.

Sexual messages for girls are often highly contradictory, which may leave girls struggling to navigate their sexuality. Sexuality can be a symbol of status for girls, resulting in tremendous pressure to engage in sex (Selikow et al., 2009; Wood, Maforah, \& Jewkes, 1998). Although girls are pushed by peers to have sex, girls who express a desire for sex or engage in "too much sex" are viewed as promiscuous (Wood, Lambert, \& Jewkes, 2007). Rather, girls receive messages that promote passivity and discourage agency in sexual relationships. South African female college youth report that girls often submit to their partner's will even when they know the behaviors are unsafe or painful (Mantell et al., 2009). A lack of assertiveness and refusal skills among South African girls may contribute to forced sex (Petersen et al., 2005). Girls low on assertiveness skills likely lack self-efficacy to refuse sexual requests and control other aspects of their sexual lives. Additionally, girls who lack agency may be unable to get out of a coercive relationship, which opens up the opportunity for repeated victimization.

Poverty can also create an environment in which sexual behavior is an economic tool. The exchange of gifts is common in relationships around the world; however, youth in poverty may depend on gifts, money, or other resources (such as access to a car) from their partner to meet basic needs such as food, shelter, and education (in the form of school fees, uniforms, etc.; Heise et al., 1995; Kaufman \& Stavrou, 2004). Research focusing on girls in South Africa found that some girls use their agency to choose partners who are able to provide financial support and material goods; however, this agency does not transfer to the behaviors that occur within those relationships (Jewkes \& Morrell, 2012). Such dependence may propagate sexual violence because youth who depend on the support of their partner may feel obligated to submit to their partners desires or fear that they would lose their partners financial support if they refused them.

In cultures where sexuality is looked at with secrecy and shame, youth may be hampered from exploring their sexuality and developing the skills and knowledge they need to be efficacious in their sexual lives. Despite pressure to engage in sex from peers, there continues to be strong disapproval of sex and cultural taboos on talking about sex within families, which diminishes sexual agency and reduces youths' likeliness to 
engage in safe sex out of fear that safe sex practices will leave evidence for parents of their sexual activity (such as condoms or birth control prescriptions; Lesch \& Kruger, 2005). For South African girls, sexual agency within a romantic relationship is rare. About three-quarters of girls fear beatings if they refuse to have sex with their boyfriends and about two-thirds fear their boyfriends would leave them if they refused (Jewkes et al., 2001). Nevertheless, fostering control in one's sexual life can promote healthy sexual lives, reducing risky sexual behaviors and increasing satisfaction (Kiefer \& Sanchez, 2007; Soet, Dudley, \& Dilorio, 1999). Although communication with peer role models and family (Mueller et al., 2010) can reduce risky sexual behaviors, sexual communication is uncommon in South Africa (Lesch \& Kruger, 2005; Wood et al., 2007).

\section{The current study}

The current study aimed to examine whether having high self-efficacy in sexual situations may reduce the risk for forced sexual experiences among South African youth. Given that forced sexual encounters are not volitional, self-efficacy prior to a forced sexual encounter may not be protective in these situations, particularly if violence or threats of violence occur. Furthermore, it may be that youth who have high levels of self-efficacy have other skills that may be protective against forced sex. The current study aimed to disentangle the relationship between sexual situation selfefficacy and experiences of forced sex, by looking at both between-person differences in self-efficacy and fluctuations in individual levels of self-efficacy up to 6 months prior to reports of forced sex using multilevel modeling. Lastly, we will test for differences in this relationship for male and female youth.

\section{Method \\ Participants}

Data for the current study come from a larger study examining the efficacy of a schoolased sub- stance use and HIV prevention program in South Africa (Smith et al., 2008). The present etiological study will be limited to youth from five control schools to ensure that the results are not confounded by the treatment condition. All schools were located in a fairly homogeneous (primarily "colored," low-income residents), periurban township near Cape Town, South Africa, established during the apartheid era. (Note: As part of the apartheid regime, the Population Registration Act of 1950, which was repealed in 1991, divided the population of South Africa into Black [African], White, Indian, and colored [derived from Asian, European, Khoisan, and African ancestry]. These classifications persist today and were used for the current study as the terms are easily understood by most South Africans and people generally identify with one of the four groups. Furthermore, a legacy is that many people presently living in impoverished social and environmental contexts are black and colored; thus, race is still a strong indicator for socioeconomic status in South Africa.)

Three consecutive cohorts of learners beginning Grade 8 in March of 2004, 2005, and 2006 were recruited for the control group, with 3,539 youth providing assent at baseline (98.6\%). Observations occurred every 6 months for a total of five (cohort 3), six (cohort 2), or eight (cohort 1) possible measurement occasions (waves) per participant. Because predictors were not measured prior to baseline, 331 youth

\section{http://repository.uwc.ac.za}


who were sexually active at baseline were excluded from the sample to ensure no prior experiences of forced sex. This restriction increases confidence in the direction of the results. Excluded youth were more likely to be male (79\%) and were older (mean age $=14.4$ ), and nearly a third $(31 \%)$ reported that their last sexual encounter was forced. Although attrition was approximately $10 \%$ of youth between each wave, the majority of the nonexcluded youth $(n=3,206)$ participated in at least two sequential observations and thus were included in the final analyses. However, a valid outcome response was missing for 313 youth for whom no other pairs of observations were available. Thus, the final sample consisted of 2,893 youth participating in 10,379 observations across the eight waves of data collection. At baseline (Wave 1), the majority of participants were female (55\%) and identified as colored (90\%). The remaining participants were Black (5\%), White (4\%), or other ethnicity (1\%). On average, participants were 13.8 years old at baseline (range 12-18).

\section{Data collection procedures}

Letters explaining the study were sent home with youth to obtain passive parental consent. Parents were provided information on how to opt out of the study if they did not wish for their child to participate. Research staff explained the study to youth and provided them with written information to obtain participant assent. All youth had the opportunity to withdraw from the study at each wave. No parents refused participation, and $1.4 \%$ of participants refused assent at baseline.

Beginning in the eighth grade, assenting youth completed questionnaires every 6 months for up to 4 years using personalized digital assistants (PDAs). Questionnaires were available in both English and Afrikaans (the two main languages spoken in the Western Cape). The study protocol was approved by the institutional review boards of the Pennsylvania State University (United States) and Stellenbosch University (South Africa).

\section{Measures}

\section{Forced sex}

All youth who reported that they "ever had sex" were asked a series of follow-up questions about their last sexual encounter, including a single question about whether or not they were "forced to have sex" at that time and when their last sexual encounter occurred. Youth were coded as having forced sex at a given wave if they reported that the forced sex occurred within the last 6 months. Forced sex that was reported to occur more than 6 months ago was coded as missing as this event likely proceeds the predictor variables measured at the prior wave (as each wave was 6 months apart). This ensures that the report of forced sex occurs subsequent to the prior wave. Youth who responded that they were not forced to have sex or reported that they never had sex were coded as not having forced sex.

\section{History offorced sex}

Because the experience of forced sex may influence youth's self-efficacy, a variable was created to account for past forced sexual experiences. The variable is a time-varying count of all reports of forced sexual experiences at each prior wave (thus lagging one wave behind the outcome measure). Youth who never experience forced sex will have 
a score of zero on all measurement occasions. At Wave 8, the maximum value for this variable is six as those sexually active prior to Wave 1 were excluded from the sample; thus, forced sex could only be reported in six waves prior to Wave 8.

\section{Sexual situation self-efficacy}

The mean of four items measuring youths' sexual situation self-efficacy including knowing ways to express love other than sex; ensuring a condom is used even if their partner did not want to and when she or he has been drinking alcohol; and refusing sex when they do not wish to have sex, was used to construct a sexual agency scale. Each item was measured on a 5-point Likert scale ranging from strongly disagree

(o) to strongly agree (4). Items were combined to create a sexual situation self-efficacy scale. Scale reliability was very good at all waves, with Cronbach's alpha ranging from .76 (95\% confidence intervals [CI]: $0.75,0.78$ ) at Wave 1 to 0.80 (95\% CI: $0.78,0.83$ ) at Wave 6. (CI computed using the procedure were documented in MaydeuOlivares, Hartmann, and Coffman [2007].)

\section{Analytic Strategy}

A multilevel Bernoulli regression model was fit using HLM 6.08 (Raudenbush, Bryk, \& Congdon, 2004) to test the study hypotheses. Although the use of longitudinal data is critical in understanding developmental processes, regression models that do not account for the nested structure (i.e., observations within persons) of longitudinal data may produce biased results. For example, multiple observations for the same individual are likely more correlated than observations from different individuals; however, ordinary least squares regression assumes that each observation is independent. Furthermore, more proximate observations for the same individual will be more highly correlated than more distal observations. A multi-level model nesting observations within individuals is used to account for this inherent dependency. An additional level of dependence is present in the current data, as youth attending the same school may be more similar to each other than those attending other schools. The school-level nesting was accounted for by estimating fixed effects for each school (dummy coded) in the level 2 model.

Time variables are centered, and individual means for each of the time variables were included in the level 2 model to control for differences in the number of observations in which individuals participate. A random intercept was included at level 1 to allow individuals to vary in their risk of experiencing forced sex at Wave 4. Individual's selfefficacy and history of forced sex vary with time and thus were included in the level 1 model along with measures of time. A random coefficient for both linear and quadratic time was included, allowing individuals to vary in their change in experiences of forced sex over time.

To differentiate within- and between-person effects, self-effic acy was centered around the individual's mean with the individual's mean value across observations included in the level 2 model. Thus, for self-efficay, the level 1 estimate reflects how changes in an individual's self-efficacy relative to their average level influence their subsequent risk of experiencing forced sex, while the level 2 estimate represents how differences between individuals in levels of self-efficacy across time influence risk of forced sex. Individual 
mean sexual agency (level 2) is grand mean centered to allow coefficients for the other variables to be interpreted as the effect of the variable at the average level of self-efficacy.

Because the experience of forced sex may influence youth's self-efficacy, we control for past experiences of forced sex in the level 1 model. This allows the meaning of the selfefficacy coefficient to reflect the effect of individual variation in levels of self-efficacy on forced sex when there were no prior reports of forced sex (i.e., when an individual has had o past experiences of forced sex).

Lastly, gender is also included in the level 2 model (female $=0$, male $=1$ ), as past research has shown that both levels of self-efficacy and rates of forced sex differ for males and females. Gender was grand mean centered to allow coefficients for the other variables to be interpreted as the effect of the variable across males and females. An interaction between gender and self-efficacy was examined in a separate model.

Because the dependent variable is dichotomous, all regression estimates reflect the additive effect of the variable on the log odds of youth experiencing forced sex, controlling for all other variables. For the key findings, odds ratios (OR) will also be presented to aid in interpretation.

\section{Results}

\section{Descriptives}

Descriptive statistics for the study are presented in Table 1. On average, participants were 13.84 years old at baseline and participated in three measurement occasions. Just under half of the participants were male (45.4\%), and $31.9 \%$ of participants reported that they initiated sex at some point during the course of the study. Overall, $2.8 \%$ girls and $9.5 \%$ of boys reported forced sex at least once. Incidences of forced sex were higher among sexually active youth with $10.6 \%$ of girls and $25.2 \%$ of boys who ever had sex reporting forced sex at any wave. Forced sex during the past 6 months was reported at 1.4\% of all observations across youth.

\section{Multilevel Model}

The model revealed significant linear and quadratic time trends, suggesting that on average, reports of forced sex increase with time, $t(2,892)=8.67, p<.001$, but that the rate at which risk increases attenuates over time, $\mathrm{t}(2,892)=-15.88, \mathrm{p}<$ .001. The final level 1 model with level 2 individual means is shown in Table 2.

\section{School-level dependence}

Dummy variables for each school were included in the model simultaneously. Individuals attending two of the schools had lower odds of experiencing forced sex compared to the reference school (Table 2). The Wald test was conducted to assess whether including the school dummy variables provided a significant contribution to the overall model. The test was significant, $\mathrm{v}^{2}(4)=38.04, \mathrm{p}<.001$, suggesting that the inclusion of schools explains more variance over and above the level 2 model (Table 2). The school variables are retained in the model to control for school-level variance in experiences of forced sex.

\section{http://repository.uwc.ac.za}


Descriptive Statistics

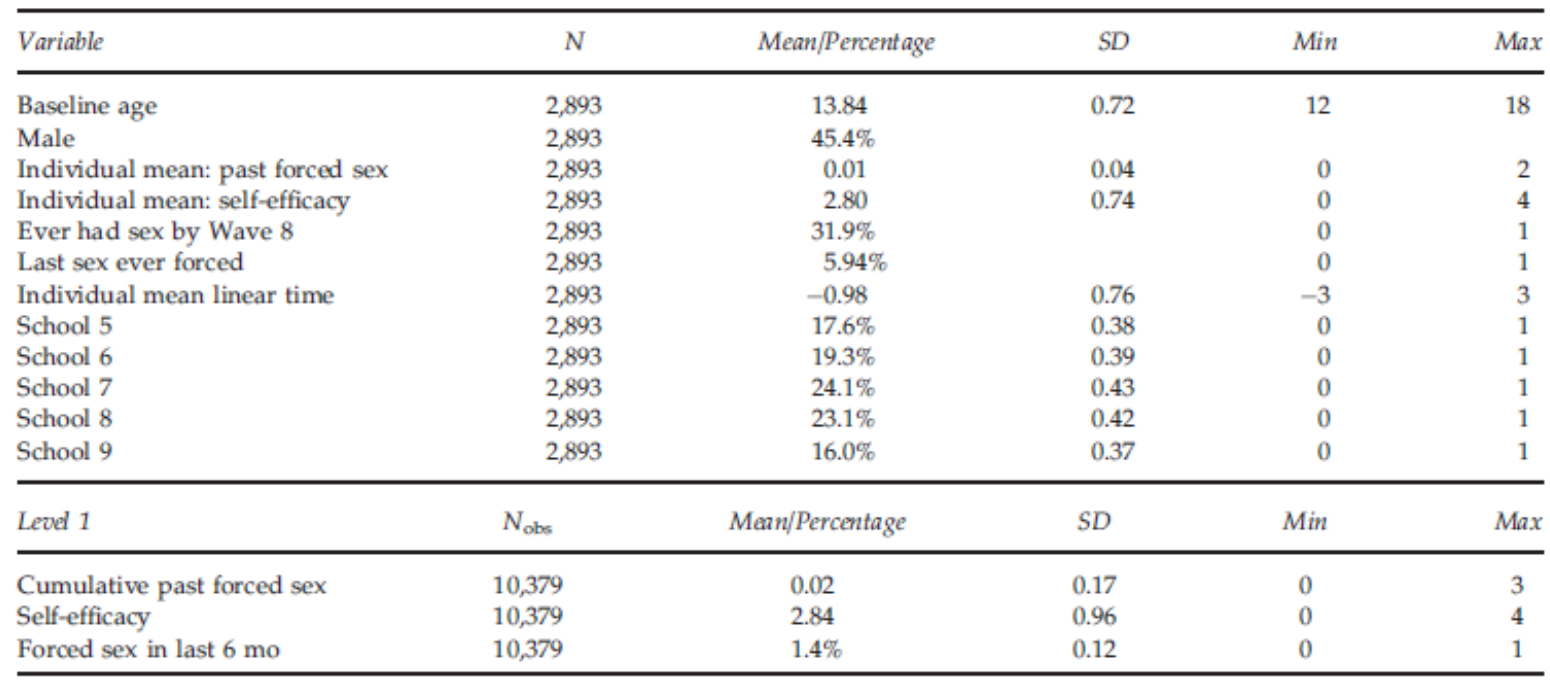

TABLE 2

Hierarchical Logistic Regression Estimates (Standard Errors) for Model Predicting Forced Sex Among South African Youth

\begin{tabular}{|c|c|c|c|}
\hline & $\begin{array}{c}\text { Level } 1 \text { Model with Level } 2 \text { Means } \\
\text { Estimate (SE) }\end{array}$ & $\begin{array}{l}\text { Two-Level Model } \\
\text { Est imate }(S E)\end{array}$ & $\begin{array}{c}\text { Three-Level Model } \\
\text { Est imate (SE) }\end{array}$ \\
\hline \multicolumn{4}{|l|}{ Level 1 (Observation level) } \\
\hline Past forced sex experiences & - & $1.03(0.15)^{*+*}$ & $0.93(0.15)^{*+24}$ \\
\hline Self-efficacy & - & $-0.19(0.05)^{* t}$ & $-0.18(0.05)^{t *}$ \\
\hline Linear time & $0.11(0.05)^{*}$ & $0.13(0.02)^{*+1+}$ & $0.17(0.02)^{+\times 4}$ \\
\hline Quadratic time & $-0.05(0.02)^{*}$ & $-0.07(0.01)^{*+*}$ & $-0.07(0.01)^{+20 t}$ \\
\hline \multicolumn{4}{|l|}{ Level 2 (Person level) } \\
\hline Intercept & $-5.28(0.20)^{x+*}$ & $-5.11(0.17)^{+x+*}$ & $-5.10(0.18)^{+2 x}$ \\
\hline Baseline age & - & $0.19(0.05)^{* *}$ & $0.17(0.05)^{* t}$ \\
\hline Male & - & $0.92(0.06)^{x+*}$ & $0.93(0.06)^{*+2}$ \\
\hline Mean linear time & $-0.68(0.08)^{x+*}$ & $-0.47(0.06)^{x+2}$ & $-0.45(0.06)^{+2 x}$ \\
\hline Mean quadratic time & $0.26(0.12)^{t+* t}$ & $0.26(0.05)^{* *}$ & $0.28(0.05)^{+20}$ \\
\hline Mean self-efficacy & $-0.87(0.09)^{* * *}$ & $-0.53(0.04)^{t+* t}$ & $-0.51(0.04)^{\text {tetet }}$ \\
\hline \multicolumn{4}{|l|}{ Level 3 (School level) } \\
\hline School 6 & - & & $-0.02(0.11)$ \\
\hline School 7 & - & & $-0.42(0.10)^{+2 t}$ \\
\hline School 8 & - & & $-0.04(0.10)$ \\
\hline School 9 & - & & $-0.33(0.12)^{* t}$ \\
\hline \multicolumn{4}{|l|}{ Wald Test (for school level) } \\
\hline$\chi^{2}$ & & & $38.04^{* * *}$ \\
\hline$d f$ & & & 4 \\
\hline Random Effects & Variance Component (SD) & $n t(S D)$ & Variance Component (SD) \\
\hline Intercept & $1.73(1.31)$ & & $1.17(1.08)$ \\
\hline Linear time & & & $0.04(0.21)$ \\
\hline Quadratic time & & & $0.01(0.11)$ \\
\hline
\end{tabular}

$* * p<.001 ; * * p<.01 ; * p<.05$.

Between-person effects. The results for the three-level nonlinear model are included in Table 2. On average, the odds that an individual with mean level self-efficacy and no history of forced sex will experience forced sex is 0.006, suggesting that most youth do not report forced sex. Being male is associated with a $153 \%$ increase in the odds of experiencing forced sex compared to females $(\mathrm{OR}=2.53)$ when holding all other variables at their mean level. Each unit increase in mean level of self-efficacy, relative to one's peers, decreases the odds of experiencing forced sex. Thus, individuals who report average self-efficacy scores of 3.8 across time are $60 \%$ less likely to report forced sex than youth reporting average levels of self-efficacy (score of 2.8). 


\section{Within-person effects}

Controlling for stable individual differences and time, youth are less likely to experience forced sex when they report higher self-efficacy relative to their own mean level of self-efficacy. This effect did not differ for males and females; thus, the interaction term was dropped from the model. At times when youth have no history of forced sex, one's odds of experiencing forced sex is $17 \%$ lower when their self-efficacy is one unit higher than their usual compared to times when they report their average levels of self-efficacy $(\mathrm{OR}=0.831)$. However, at times when youth report one past forced sex experience, their odds of experiencing forced sex again is $153 \%$ higher than the odds of reporting the first forced sexual encounter $(\mathrm{OR}=2.53)$. When youth have no history of forced sex and report levels of self-efficacy one point lower than their own mean, the probability of experiencing forced sex is .007. When youth have experienced forced sex once before, the same deviation from their own mean is associated with a .018 probability of reporting forced sex (Figure 1).

The influence of deviations in individual levels of self-efficacy is particularly strong for youth who already have lower mean levels of self-efficacy relative to their peers (Figure 2). Youth who are 1.2 points below the mean on self-efficacy (score of 1.6) have a .011 probability of experiencing forced sex in the next 6 months when they are at their mean level of self-efficacy. A one-unit reduction from the mean for these youth is associated with a .013 probability of experiencing forced sex.

In contrast, youth with high levels of self-efficacy (1.2 units above the mean) have a .003 probability of experiencing forced sex when they are at their average level and a .005 probability when they report levels of self-efficacy one point lower than their usual. Although the overall probability of experiencing forced sex at any given time is low, the same individual's risk is over twice as high when their levels of self-efficacy are one unit lower than usual compared to when their self-efficacy is one unit higher than usual. 


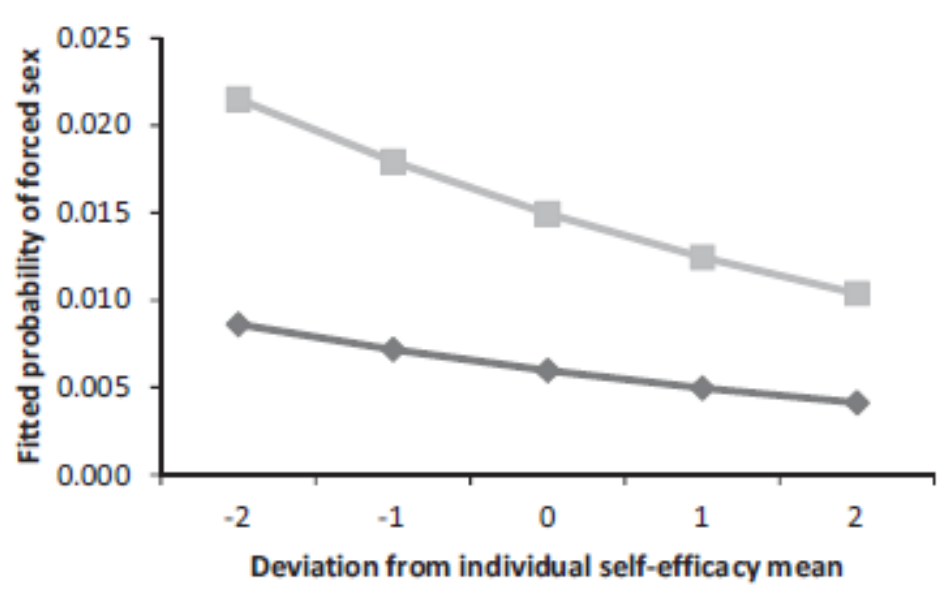

$\longrightarrow$ No History of Forced Sex $\quad-$ History of Forced Sex

FIGURE 1 Fitted probabilities of experiencing forced sex by deviations from individual mean levels of self-efficacy, for youth with a history of forced sex compared to those with no history of forced sex when youth have a mean self-efficacy of 2.8 across time (estimates are averaged across gender, schools, and controlling for time).

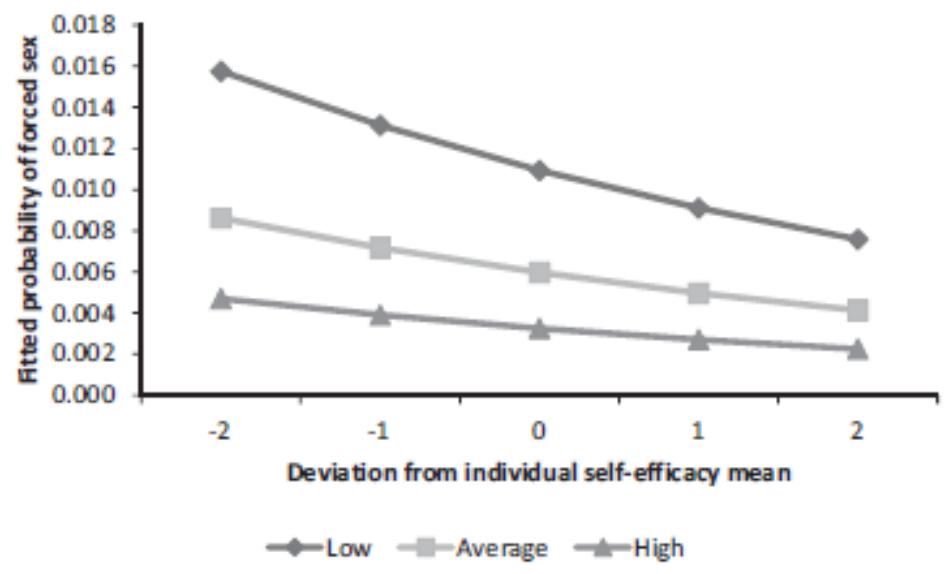

FIGURE 2 Fitted probabilities of experiencing forced sex by deviations from individual means, for youth with high (score of 4), average (score of 2.8), and low (score of 1.6) mean levels of self-efficacy, for youth with no history of forced sex (estimates are averaged across gender, schools, and controlling for time).

\section{Discussion}

The current findings support the importance of sexual situation self-efficacy for reducing the risk of forced sexual experiences, over and above the effect of past forced sexual experiences. Although past forced sexual experiences are a strong risk factor for future forced sex, low levels of self-efficacy increased youth's risk of forced sex at times when youth had no prior forced sexual experiences. Youth's reports of sexual situation self-efficacy were variable, with most youth feeling either uncertain (i.e., neither agreeing nor disagreeing with statements) or fairly confident in their ability to influence sexual situations. The lower prevalence of particularly poor self-efficacy is promising given cultural norms that discourage discussions about sex and promote gender inequalities (Jewkes, Wood, \& Duvvury, 2010; Lesch \& Kruger, 2004). Nonetheless, there is room for substantial improvements in youths' sexual situation self- 
efficacy. Overall, the risk of experiencing forced sex was higher for youth who had poorer self-efficacy relative to peers.

The results from the current study suggest that youth's levels of self-efficacy vary across time. Youth were at increased risk of forced sex at times when they report lower than usual levels of self-efficacy. The stronger effect of decreases in self-efficacy for those with low average level self-efficacy suggests that interventions should pay particular attention to youth with low self-efficacy at base-line. These youth may be at particular risk for experiencing forced sex. The lack of self-efficacy may prevent assertiveness in coercive sexual encounters. These results are supported by previous research that suggests that self-efficacy to control aspects of one's sexual encounter, such as convincing a partner to use a condom, can be protective against forced sex (Maharaj \& Munthree, 2007) or unwanted sex (Sionean et al., 2002). Given these findings, youth may benefit from interventions that address self-efficacy at multiple time points rather than in one or two subsequent lessons because this may help improve youth's average levels of self-efficacy and also attenuate any declines in selfefficacy.

The importance of within-person fluctuations in self-efficacy on proximal outcomes has been demonstrated in other domains, including physical activities (Minbashian \& Luppino, 2014) and cognitive performance (Neupert \& Allaire, 2012). Although little research has examined fluctuations in adolescents' self-efficacy related to sexual health, these fluctuations are likely due to changes in skills and contextual factors, such as relationship status, partner characteristics, and peer influences. For example, youth in a relationship may anticipate being in a situation where coercion is likely to occur, which may lower their self-efficacy at the time. This may be particularly relevant in relationships with an older partner or a partner who provides resources or economic support (Kaufman \& Stavrou, 2004). Youth in these relationships may feel that they cannot refuse their partners requests in fear that their partner will leave them. Future research should examine the factors that contribute to this fluctuation in sexual situation self-efficacy.

Despite the exclusion of early sexual initiators (i.e., prior to Wave 1), reports of forced sex remain high. Overall, while youth had a forced sexual encounter in less than $2 \%$ of the observations, over the course of the study, nearly $6 \%$ of all youth and $20 \%$ of sexually active youth reported forced sex on at least one occasion. Experiences of forced sex in this sample appear lower than those reported in other studies, although they are not directly comparable. In a representative sample of Western Cape high school learners, 8.8\% reported ever experiencing forced sex (Reddy et al., 2010). In a nationally representative sample, $8.6 \%$ of youth reported experiencing forced sex in the last year (Andersson et al., 2004). Although each of these studies refers to a different length of time, both studies reported rates of forced sex among all youth. We were unable to capture forced sexual experiences for participants who were missing from data collection at a particular wave or who dropped out of the study, which may account for the lower estimate compared to other studies. Furthermore, given the exclusion of youth who were sexually active at Wave 1 from our sample, many of whom experienced forced sex, the actual rates of forced sex are likely substantially 
higher. Nonetheless, the proportion of youth experiencing forced sex, particularly among those who ever had sex, is alarming.

An often unstated and potentially false assumption of gender inequality research is that encouraging sexual prowess in boys equates to sexual control for boys. Although social messages of sexuality differ for both male and female youth, the impact on both their efficacy and ability to control their sexual encounters may be the same. A man who does not have sex when he desires it is seen as weak (Jewkes, Penn-Kekana, and Rose-Junius (2005), while responding to sexual propositions in a hesitant and ambiguous manner is considered feminine (Wood et al., 2007). These messages may limit boys' ability or willingness to refuse sex because of fear of stigmatization; thus, they may be more likely to report any unwanted sexual proposition as forced sex, even if no refusal attempt was made. Conversely, girls are discouraged from negotiating the terms of sex (Ajuwon, 2005; Kim, Kols, Nyakauru, Marangwanda, \& Chibatamoto, 2001; Petersen et al., 2005) and are taught that they do not have the right to refuse sex with their boyfriends (Andersson et al., 2004). Both male and female South African youth report difficulty in negotiating safe sex (Buthelezi et al., 2007). Given the large proportion of male youth reporting forced sex, our results suggest that programs should aim to increase sexual situation self-efficacy among boys and girls. Additionally, further exploration of self-efficacy in preventing forced sex is warranted, particularly in respect to potential gender differences.

\section{Need for more targeted intervention}

Given the high rates of forced sexual encounters in South Africa, it is likely that most sexual health interventions will have many participants who have already experienced forced sex, which further increases youths' risk of future forced sexual experiences. For these students, traditional approaches to bolstering self-efficacy may be less effective. Although the current study did not examine the impact of forced sex on self-efficacy beliefs, it is likely that forced sexual experiences contribute to a further decline in selfefficacy. Future research should examine how interventions can address the potential impact of previous forced sexual experiences on self-efficacy to help prevent repeated victimization.

Characteristics of one's partner likely contribute to feelings of self-efficacy. Interventions targeting respectful relationships and reducing dating violence in early adolescents may provide a context that encourages both the development of selfefficacy and opportunities to have those beliefs validated. Youth who experience forced sex are more likely to also perpetrate forced sex (Andersson \& Ho-Foster, 2008; Njue, Askew, \& Chege, 2005). Consequently, it is important to reduce forced sex among both boys and girls and to improve relationship dynamics in order to stop the cycle.

Stepping Stones is an intervention that targeted late adolescents and young adults and aimed to improve gender equality within relationships as a means to reduce risky sexual behavior and HIV and AIDS infections in South Africa. Young men who participated in Stepping Stones reported less physical and sexual violence 2 years after program when compared to the control group (Jewkes et al., 2008). These findings suggest that interventions in South Africa may be able to reduce sexual victimization 
among youth, particularly if men are included. However, it is unclear whether similar results would be found if the intervention was implemented with a younger sample, such as used in the current study. Furthermore, young women did not report a similar reduction in their experiences of physical and sexual victimization. The patriarchal norms in South Africa may allow men to make changes in their sexual lives more easily than women. However, reduced incidences of herpes simplex virus-2 among women suggest that women were able to gain some control over their sexual encounters (Jewkes et al., 2008).

Another program to prevent dating violence in the United States, Safe Dates, targets early and mid-adolescents and has been promoted by the World Health Organization (WHO) (2010) as an effective strategy to prevent partner violence in adolescents. A similar program is currently being developed in South Africa, but an evaluation of the program is not yet available (Russell et al., 2014). Safe Dates aims to prevent and reduce all types of dating violence among male and female youth (Foshee et al., 1998). Evaluations of Safe Dates show a positive impact among youth who had previously experienced dating violence on dating violence norms, gender stereotyping, nondestructive anger coping skills, more perceived negative consequences for dating violence, and knowledge of available services for victims and perpetrators. The program also had effects on actual physical and sexual violence at the 4-year follow-up (Foshee, Benefield, Ennett, Bauman, \& Suchindran, 2004). The factors addressed by Safe Dates are very relevant to South African youth and may help to reduce forced sex among both boys and girls.

Despite the promise of interventions such as Stepping Stones and Safe Dates, incorporating components of these interventions, particularly those related to healthy relationships and gender equality, into more comprehensive interventions may be more realistic and efficient. The ability to use skills learned in dating violence prevention programs may be undermined by other risky behaviors. For example, Russell et al. (2014) found that heavy drinking hindered girls' conflict resolution skills, suggesting that addressing heavy drinking concurrently with dating violence may be more effective than addressing issues of gender equality, dating violence norms, and conflict resolution alone. Given the overlap of risk and protective factors in many problem behaviors (i.e., risky sex, substance use, delinquency, etc.; Botvin \& Griffin, 2004) and the limited resources that schools have for interventions, research should focus on how the prevention of dating violence can be incorporated into universal prevention programs.

\section{Limitations}

Although the current study provides important insight for prevention of forced sex in South Africa, several limitations should be noted. Forced sex was measured with a single item that asked learners whether their last sexual encounter was forced. It is possible that some participants experienced forced sex that was not captured. A participant who had more than one sexual encounter during a given 6-month period may not report forced sex if it did not occur at their most recent sexual encounter. The use of multilevel modeling captures multiple forced sex experiences across waves, but may exclude multiple experiences within a shorter time frame.

\section{http://repository.uwc.ac.za}


As discussed in the introduction, forced sex may not have the same meaning for all youth. In South Africa, many youth feel it is acceptable to "persuade" someone into sex, oftentimes using methods of verbal coercion or physical force (Wood et al., 2007). Furthermore, evidence from other African nations suggests that some men may report being forced to have sex when women dress seductively (Moore, Madise, \& AwusaboAsare, 2012), invoking the stereotype that men cannot resist sex when aroused (Petersen et al., 2005). Therefore, youth who report being forced to have sex may not perceive the experience to be problematic. Limitations of the data do not permit exploration of the severity of the forced sex experience (use of violence, blackmail, relationship to partner, etc.) nor the characteristics of the perpetrator. Predictors of forced sex may vary depending on the context of the forced sex event. For example, sexual efficacy may protect youth from verbally coercive forced sex, but have little impact on violent sexual assaults. It is possible that those youth who experienced the most severe forms of forced sex were more likely to drop out of school due to psychological and physical impact of the experience. These youth would not be captured by this study as only youth attending school were surveyed. Future research should examine the characteristics of the forced sex experience and how those characteristics relate to predictors of forced sex.

Given the high rates of reported forced sex, some researchers have questioned the accuracy of forced sex prevalence estimates. Among pregnant South African girls, Jewkes et al. (2001) found that some girls reported both engaging in sex because of curiosity and that sex was forced. The authors speculated that these youth may report higher rates for forced sex because of social desirability or that these youth may have been willing to have sex under different circumstances. However, girls who were sexually active, but not pregnant did not report seemingly contradictory explanations for sex, suggesting that regret due to the resulting pregnancy or the circumstances around the sexual event may be the most likely explanation. In the current study, over-reporting of forced sex among girls does not appear to be a problem, as most girls do not report that sexual intercourse was forced.

More often researchers express concern of underrepresenting experiences of forced sex, citing youth's fear of others finding out and cultural beliefs that forced sex is a private matter. In cases of child rape, reporting of rape by a family member may result in poverty, family shame, and family disruption (Jewkes et al., 2005). These consequences are often seen as worse than rape itself, thus preventing the report of rape. Jejeebhoy and Bott (2003) report that in interview-based research, nonconsensual sex is likely underreported due to the sensitivity and traumatic nature of the event. However, the use of PDAs in the current study likely increased the accuracy of forced sex reports. Rates of reporting tend to be substantially higher in computer-assisted interviews, where greater degrees of confidentiality are insured (Rumakom, Guest, Chinvarasopak, Utarmat, \& Sontanakanit, 2005). However, most studies focus on reporting of forced sex among women and girls. The factors influencing accurate reports of forced sex among boys are unknown. 
Participants in this study were primarily colored (of mixed ancestry) youth in one township in South Africa, limiting our ability to generalize our findings to other youth both within and beyond South Africa. Study results and implications should be interpreted in light of these limitations.

\section{Conclusions}

The current study highlights the importance of self-efficacy to control one's sexual encounters in reducing youth's vulnerability to forced sex and provides insight on potential targets of future interventions. Given the significance of both mean levels of self-efficacy and changes within one's own levels of self-efficacy, future studies should examine what influences the development of self-efficacy and how interventions can promote self-efficacy to control sexual encounters among youth. Youth who experience forced sex are more likely to also perpetrate forced sex (Andersson \& Ho-Foster, 2008; Njue et al., 2005). Consequently, it is important to reduce forced sex among both boys and girls and to improve relationship dynamics in order to stop the cycle. Interventions that aim to reduce first and repeated forced sexual experiences are critical in South Africa.

Extensive research is needed on the experiences of forced sex in South Africa, particularly among boys. Some researchers have suggested that forced sex among boys may be qualitatively different and less severe than forced sex among girls (Sikweyiya \& Jewkes, 2009). Conversely, the WHO reported that sexual violence among boys and men is a serious problem (Krug et al., 2002). The exclusion of boys from many studies has prevented a clear understanding of these youths' experience and may inadvertently preserve beliefs that sexual violence is a women's issue. Researchers should be aware of their own assumptions and be cautious that their research is guided by theory and evidence so that stereotypes and misconceptions are not perpetuated. 


\section{References}

Abma, J., Driscoll, A., \& Moore, K. (1998). Young women's degree of control over first intercourse: An exploratory analysis. Family Planning Perspectives, 2O, 12-18. doi:10.2307/2991518

Ajuwon, A. J. (2005). Attitudes, norms and experiences of sexual coercion among young people in Ibadan, Nigeria. In S. J. Jejeebhoy, S. Iqbal, \& S. Thapa (Eds.), Sex without consent: Young people in developing countries (pp. 96-104), New York, NY: Zed Books.

Anderson, L. A., \& Whiston, S. C. (2005). Sexual assault education programs: A metaanalytic examination of their effectiveness. Psychology of Women Quarterly, 29, 374-388. doi:10.1111/j.1471-6402.2005.00237.x

Andersson, N., \& Ho-Foster, A. (2008). 13,915 reasons for equity in sexual offences legislation: A national school-based survey in South Africa. International Journal of Equity in Health, 7. Retrieved October 14, 2010, from http://www.equityhealthj.com/content/7/1/20 doi:10.1186/1475-9276-7-20

Andersson, N., Ho-Foster, A., Matthis, J., Marokoane, N., Mashiane, V., Mhatre, S., .. . Sonnekus, H. (2004). National cross sectional study of views on sexual violence and risk of HIV infection and AIDS among South African school pupils. British Medical Journal, 329, 952-954. doi:10.1136/bmj.38226.617454.7C

Andersson, N., Paredes-Solis, S., Milne, D., Omer, K., Marokoane, N., Laetsang, D., \& Cockcroft, A. (2012). Prevalence and risk factors for forced or coerced sex among school-going youth: National cross-sectional studies in 10 southern African countries in 2003 and 2007. British Medical Journal, 2, e000754. doi:10.1136/ bmjopen-2011-000754

Bandura, A. (1977). Self efficacy: Toward a unifying theory of behavioral change. Psychological Review, 84, 191- 215. doi:10.1037/0033-295X.84.2.191

Bandura, A. (1989). Self efficacy: Human agency in social cognitive theory. American Psychologist, 44, 1175-1184. doi:10.1037/o003-066X.44.9.1175

Botvin, G. J., \& Griffin, K. W. (2004). Life skills training: Empirical findings and future directions. The Journal of Primary Prevention, 25, 211-232. doi:10.1023/B: JOPP.0000042391.58573.5b

Brown, A. L., Testa, M., \& Messman-Moore, T. L. (2009). Psychological consequences of sexual victimization resulting from force, incapacitation, or verbal coercion. Violence Against Women, 15, 898-919. doi:10.1177/1077801209335491

Buthelezi, T., Mitchell, C., Molestane, R., De Lange, N., Taylor, M., \& Stuart, J. (2007). Youth voices about sex and AIDS: Implications for life skills education through the "Learning Together" project in KwaZulu-Natal, South Africa. International Journal of Inclusive Education, 11, 445. doi:10.1080/13603110701391410

Cooper, M. L., Shapiro, C. M., \& Powers, A. M. (1998). Motivations for sex and risky sexual behavior among adolescents and young adults: A functional perspective. Journal of Personality and Social Psychology, 75, 1528-1558. doi:10.1037/00223514.75.6.1528

Crown, L., \& Roberts, L. J. (2007). Against their will: Young women's nonagentic sexual experiences. Journal of Social and Personal Relationships, 24, 385-405. doi:10.1177/0265407507077228 
Daigle, L. E. (2009). The effectiveness of sexual victimization prevention among college students: A summary of "what works." Victims and Offenders, 4, 398-404. doi:10.1080/15564880903227529

De Koker, P., Mathews, C., Zuch, M., Bastien, S., \& Mason-Jones, A. (2014). A systematic review of interventions for preventing adolescent intimate partner violence. Journal of Adolescent Health, 54, 3-13. doi:10.1016/j.jadohealth.2013.08.008

Foshee, V. A., Bauman, K. E., Arriaga, X. B., Helms, R. W., Koch, G. G., \& Linder, G. F. (1998). An evaluation of Safe Dates, an adolescent dating violence prevention program. American Journal of Public Health, 88, 45-50. doi:10.2105/AJPH.88.1.45

Foshee, V. A., Benefield, T. S., Ennett, S. T., Bauman, K. E., \& Suchindran, C. (2004). Longitudinal predictors of serious physical and sexual dating violence victimization during adolescence. Preventive Medicine, 39, 1007- 1016. doi:10.1016/j.ypmed.2004.04.014

Heise, L., Moore, K., \& Toubia, N. (1995). Sexual coercion and reproductive health, A focus on research. New York, NY: Population Council. doi:10.1177/10778012980040 03002

Jaycox, L. H., McCaffrey, D., Eiseman, B., Aronoff, J., Shelley, G. A., Collins, R. L., \& Marshall, G. N. (2006). Impact of a school-based dating violence prevention program among Latino teens: Randomized controlled effectiveness trial. Journal of Adolescent Health, 39, 694- 704. doi:10.1016/j.jadohealth.2006.05.002

Jejeebhoy, S. J., \& Bott, S. (2003). Non-consensual sexual experiences of young people: A review of the evidence from developing countries. New Delhi, India: Population Council.

Jewkes, R. (2002). Intimate partner violence: Causes and prevention. Lancet, 359, 1423-1429. doi:10.1016/s0140-6736(02)08357-5

Jewkes, R., \& Morrell, R. (2012). Sexuality and the limits of agency among South African teenage women: Theorising femininities and their connection to HIV risk practises. Social Science and Medicine, 74, 1729-1737. doi:10.1016/j.socscimed.2011.05.020

Jewkes, R., Nduna, M., Levin, J., Jama, N., Dunkle, K., Puren, A., \& Duvvury, N. (2008). Impact of Stepping Stones on incidence of HIV and HSV-2 and sexual behavior in rural South Africa: Cluster randomized controlled trial. BMJ, 337, a506. doi:10.1136/bmj.a506

Jewkes, R., Penn-Kekana, L., \& Rose-Junius, H. (2005). "If they rape me, I can't blame them": Reflections on gender in the social context of child rape in South Africa and Namibia. Social Science and Medicine, 61, 303-307. doi:10.1016/j.socscimed.2005.03.022

Jewkes, R., Vundule, C., Maforah, F., \& Jordaan, E. (2001). Relationship dynamics and teenage pregnancy in South Africa. Social Science and Medicine, 52, 733744. doi:10.1016/So277-9536(oo)oo177-5

Jewkes, R., Wood, K., \& Duvvury, N. (2010). “I woke up after I joined Stepping Stones”: Meaning of an HIV behavioural intervention in rural South African young people's lives. Health Education Research, 25, 1074-1084. doi:10.1093/her/cyq062 
Kaufman, C. E., \& Stavrou, S. E. (2004). "Bus fare please": The economics of sex and gifts among young people in urban South Africa. Culture, Health and Sexuality, 6, 377-391. doi:10.1080/13691050410001680492

Kiefer, A. K., \& Sanchez, D. T. (2007). Scripting sexual passivity: A gender role perspective. Personal Relationships, 14, 269-290. doi:10.1111/j.14756811.2007.00154.x

Kim, Y. M., Kols, A., Nyakauru, R., Marangwanda, C., \& Chibatamoto, P. (2001). Promoting sexual responsibility among young people in Zimbabwe. International Perspectives on Sexual and Reproductive Health, 27, 11-19. doi:10.2307/2673800

Krug, E. G., Dahlberg, L. L., Mercy, J. A., Zwi, A. B., \& Lozano, R. (2002). World report on violence and health. Geneva, Switzerland: World Health Organization.

Lesch, E., \& Kruger, L. M. (2004). Reflections on the sexual agency of young women in a low-income rural South African community. South African Journal of Psychology, 34, 464-486.

Lesch, E., \& Kruger, L. M. (2005). Mothers, daughters and sexual agency in one lowincome South African community. Social Science and Medicine, 61, 1072-1082. doi:10.1016/j.socscimed.2005.01.005

Maharaj, P., \& Munthree, C. (2007). Coerced first sexual intercourse and selected reproductive health outcomes among young women in Kwazulu-Natal, South Africa. Journal of Biosocial Science, 39, 231-244. doi:10.1017/ Soo21932006001325

Mantell, J. E., Needham, S. L., Smit, J. A., Hoffman, S., Cebekhulu, Q., AdamsSkinner, J., ... Milford, C. (2009). Gender norms in South Africa: Implications for HIV and pregnancy prevention among African and Indian women students at a South African tertiary institution. Culture, Health and Sexuality, 11, 139-157. doi:10.1080/13691050802521155

Maydeu-Olivares, A., Hartmann, W. M., \& Coffman, D. (2007). Asymptotically distribution-free (ADF) interval estimation of coefficient alpha. Psychological Methods, 12, 157-176. doi:10.1037/1082-989X.12.2.157

Minbashian, A., \& Luppino, D. (2014). Short-term and long-term within-person variability in performance: An integrative model. Journal of Applied Psychology, 99, 898-914. doi:10.1037/ao037402

Moore, A. M., Madise, N., \& Awusabo-Asare, K. (2012). Unwanted sexual experiences among young men in four sub-Saharan African countries: Prevalence and context. Culture, Health and Sexuality, 14, 1021-1035. doi:10.1080/13691058.2012.713119

Mueller, T., Gavin, L., Oman, R., Vesely, S., Aspy, C., Tolma, E., \& Rodine, S. (2010). Youth assets and sexual risk behavior: Differences between male and female adolescents. Health Education and Behavior, 37, 343-356. doi:10.1177/1090198109344689

Neupert, S. D., \& Allaire, J. C. (2012). I think I can, I think I can: Examining the within-person coupling of control beliefs and cognitions in older adults. Psychology and Aging, 27, 742-749. doi:10.1037/ao026447

Njue, C., Askew, I., \& Chege, J. (2005). Non-consensual sexual experiences of young people in Kenya: Boys as perpetrators and victims. In S. J. Jejeebhoy, S. Iqbal, \& 
S. Thapa (Eds.), Sex without consent: Young people in developing countries (pp. 139157). New York, NY: Zed Books.

Petersen, I., Bhana, A., \& McKay, M. (2005). Sexual violence and youth in South Africa: The need for community-based prevention interventions. Child Abuse and Neglect, 29, 1233-1248. doi:10.1016/j.chiabu.2005.02.012

Raudenbush, S. W., Bryk, A., \& Congdon, R. (2004). HLM6: Hierarchical linear and nonlinear modeling. Lincolnwood, IL: Scientific Software International.

Reddy, S. P., James, S., Sewpaul, R., Koopman, F.,

Funani, N. I., Sifunda, S., ... Omardien, R. G. (2010). Umthente Uhlaba Usamila The South African Youth Risk Behaviour Survey 2008. Cape Town, South Africa: South African Medical Research Council.

Rumakom, P., Guest, P., Chinvarasopak, W., Utarmat, W., \& Sontanakanit, J. (2005). Obtaining accurate responses to sensitive questions among Thai students: A comparison of two data collection techniques. In S.

J. Jejeebhoy, S. Iqbal, \& S. Thapa (Eds.), Sex without consent: Young people in developing countries (pp. 318- 322). London, UK: Zed Books.

Russell, M., Cupp, P. K., Jewkes, R. K., Gevers, A., Mathews, C., LeFleur-Bellerose, C., \& Small, J. (2014). Intimate partner violence among adolescents in Cape Town, South Africa. Prevention Science, 15, 283-295. doi:10.1007/s11121-013-0405-7

Selikow, T. A., Ahmed, N., Flisher, A. J., Mathews, C., \& Mukoma, W. (2009). I am not "umqwayito": A qualitative study of peer pressure and sexual risk behavior among young adolescents in Cape Town, South Africa. Scandinavian Journal of Public Health, 37(Suppl 2), 107- 112. doi:10.1177/1403494809103903

Sikweyiya, Y., \& Jewkes, R. (2009). Force and temptation: Contrasting South African men's accounts of coercion into sex by men and women. Culture, Health and Sexuality, 11, 529-541. doi:10.1080/13691050902912783

Sion'an, C., DiClemente, R. J., Wingood, G. M., Crosby, R., Cobb, B. K., Harrington, K., ... Oh, M. K. (2002).

Psychosocial and behavioral correlates of refusing unwanted sex among AfricanAmerican adolescent females. Journal of Adolescent Health, 30, 55-63. doi:10.1016/S1054-139X(01)o0318-4

Smith, E. A., Palen, L. A., Caldwell, L. L., Flisher, A. J., Graham, J. W., Mathews, C., Wegner, L., \& Vergnani,

T. (2008). Substance use and sexual risk prevention in Cape Town, South Africa: An evaluation of the Health-Wise Program. Prevention Science, 9, 311-321. doi:10.1007/s11121-008-0103-Z

Soet, J. E., Dudley, W. N., \& Dilorio, C. (1999). The effects of ethnicity and perceived power on women's sexual behavior. Psychology of Women Quarterly, 23, 707723. doi:10.1111/j.1471-6402.1999.tboo393.x

South African Medical Research Council [SAMRC]. (2012, 20 December). Gender and Health Research Unit: Respect 4 U. Retrieved July 19, 2013, from http:// www.mrc.ac.za/gender/respect4u.htm

UNAIDS. (2013). South Africa: HIV and AIDS estimates (2011), Retrieved July 16, 2013, from http://www.un- aids.org/en/regionscountries/countries/southafrica/

Vundule, C., Maforah, F., Jewkes, R., \& Jordaan, E. (2001). Risk factors for teenage pregnancy among sexually active black adolescents in Cape Town. South Afri- can Medical Journal, 91, 73-80. 
http://repository.uwc.ac.za 